\title{
الثقافة السياسية وبناء الومدة الوطنية (حالة العراق)
}

\section{م.د. عبـ العظبيم مبـر هافظ / كلبة العلوم السباسبة / مامعة النهربن}

((Dr. Abdul Adhim Jabur Hafudh))

Abstract

The building of the national unity is considered as a basic element that heavily relies on the political systems and societies. One of these factors effecting the building of the national unity, is the political culture. In respect to Iraq, when a cultural policy prevails over whereof, it reinforces the political values pressuring toward subjection to the decisions of the political authority that represented the benefit of the Iraqi society in one side and the opening of political authority to the Iraqi society on the other side. This makes the relationship between the society and the authority more interactive, effective and cooperative; besides that, the seriousness of mentality on political and social upbringing that expresses the home values and nationality, leaving aside tiny things for the sake of Iraq. This leads to building the national unity.

ان بنـاء الوحدة الوطنيـة من المهمـات الاساسية التي يقع عاتقها على المجتمعات والانظمـة الأساسية، وان واحدة من

العو امل التي تؤثر في بناء الوحدة الوطنية هي الثقافة السياسية المشـاركة. وفي حالة العراق عندما تسود المجتمع العر اقي ثقافة

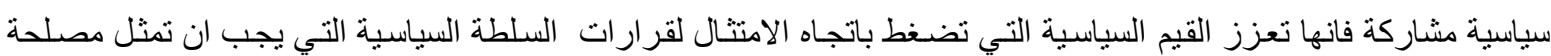
المجتمع العراقي عامـة من جهة، وانفتاح السلطة السياسية على المجتمع العر اقي من جهة اخرى، وهو مـا يجعل العلاقـة بين المجتمع والسلطة اكثر عمقا ونضجا وتفاعلا وتعاونا فضلا عن الاهتمام الجدي والفعلي في مسالة التنشئة السياسية والاجتماعية التي تعبر عن قيم الوطن والوطنية والمواطنة، والعبور فوق الانتمائات الفرعية لصالح الوطن العر اقي الامر الذي يفضي الى بناء الوحدة الوطنية.

\section{مقدمة}

إن بناء الوحدة الوطنية من المهمات الأساسية التي يقع عاتقها على المجتمعات و الأنظمـة السياسية. لأن تو افر الوحدة الوطنية في أي بلدُ يؤشر مدى ومستوى ارتفاع الاندماج الاجتماعي بين عناصره، بمعنى إن قيمـة المو اطنـة هـي المعيـار و السـمة البـارزة التي تميز هذا البلد عن ذاك. فالمجتمعـات المنقسمة والمززقـة اجتماعياً لا تتو افر فيها روح الاعتر اف بـالآخر ومن ثم تغيب فيه سمة الوحدة الوطنية، و إن النظـام السياسي وني

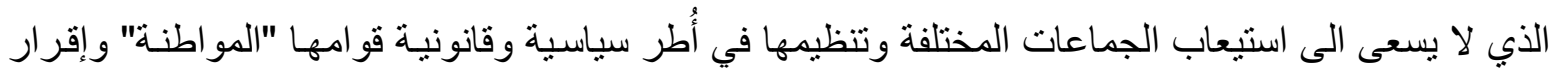
الحقوق المدنية والسياسية وتوزيع الثروة بعدالة، هو الآخر يعمل على تمزيق الوحدة الوطنية.

و إذا كانت ثمة عو امل تعمل على تحقيق بنـاء الوحدة الوطنيـة، مثل تأسيس الروابط بين الجماعات المختلفة بالاستناد الى قيم المو اطنة وتلاحمهم في كيان اجتمـاعي ـ سياسي؛ والتو اصل و التعـاون بين اعضـاء المجتمع الواحد، وتو افر نظام سياسي يقر دستوريا وقانونيا الحريات المدنية والسياسية والمشاركة السياسية في

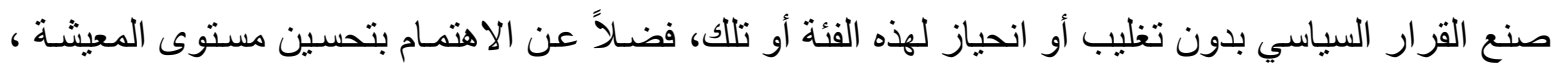
فإن للثقافة السياسية دور ها في بناء الوحدة الوطنية لايقل أهمية عن بـاقي العوامل الأخرى ، فالثقافة السياسية ترتبط بعو اطف ومشـاعر وقيم و إدر اكـات الفرد إز اء النظـام السياسـي سواءاً أكانت إيجابيـة (بنـاءه) أم سلبية 
(هدامة) ويتجسد تأثير عامل الثقافة السياسية في عمليـة بنـاء الوحدة الوطنية حيث تتو افر لها فرص التو افق

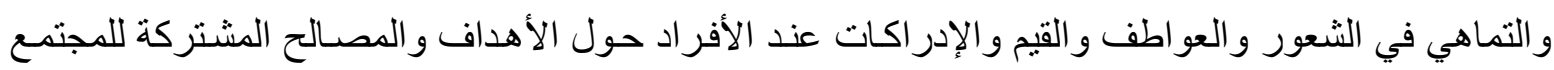
من جهة، و إن النظام السياسي يعمل على تهيئة هذه الفرص من خلال إقرار قيم الديمقر اطية من جهة أخرى. وبمـا إن التقافة السياسية تصنف الى ثقافة تقليديـة وثقافة خضـوعية وثقافة مشــاركة (مُسـاهمة) فأن

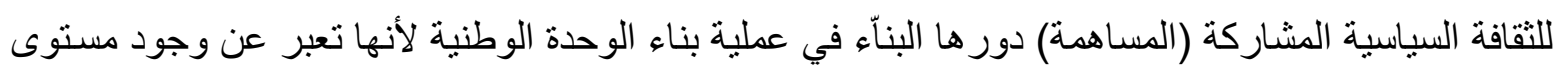

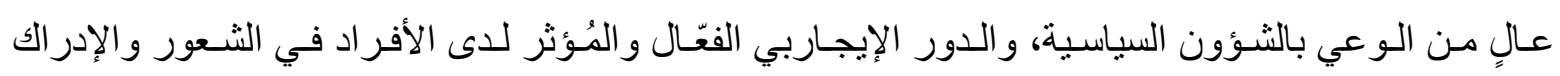

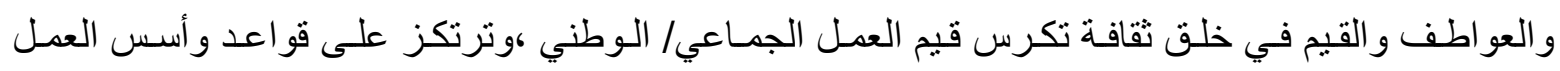
الديمقر اطي، و أساسها الإيمان بمبدأ ـ- المواطنة ـ ومـا يترتب عليها من حقوق وواجبات واعتبـار ات إنسـانية

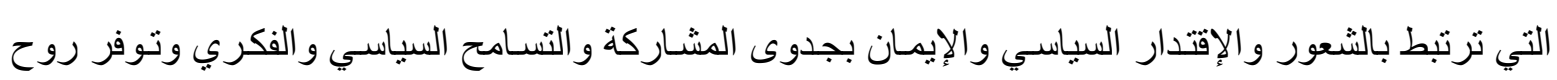
المبادرة و اللاشخصانية والثقة السياسية.

وفي حالة العراق، والحديث هنـا عن الثقافة السياسية، فقد كانت السمة السـائدة نسبياً الثقافة السلبية (الإقصائية) من قبل النظام السياسي، يقابلها الثقافة التقليدية والخضو عية من قبل المجتمع ، التي لم تستطيعا أن

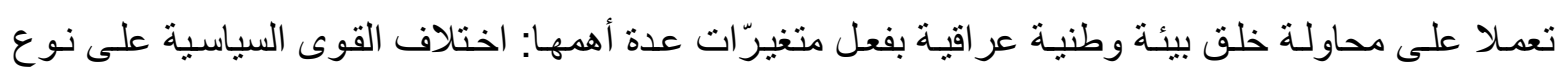
وطبيعة النظام السياسي، وفهم كل قوة سياسية/ اجتماعية / مذهبية بأنها لها الحق وحدها في الحكم، وعدم

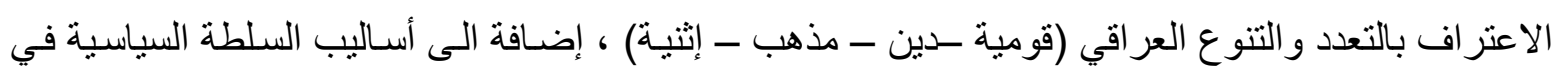

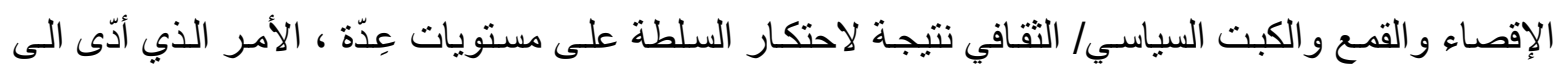

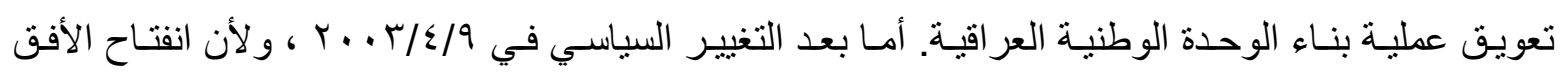
السياسي/ والثقافي يفترض أن يهيء فرص ثقافة سياسية مشاركة ومن ثم بناء وحدة وطنية عر اقية هُو المُعِول

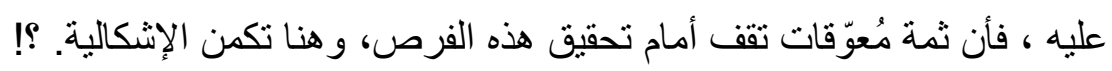

ينطلق البحث مـن فرضية مفادهـا: إن تو افر ثقافـة سياسية وطنيـة مشـاركة عـابرة للتقافـات الفرعيـة

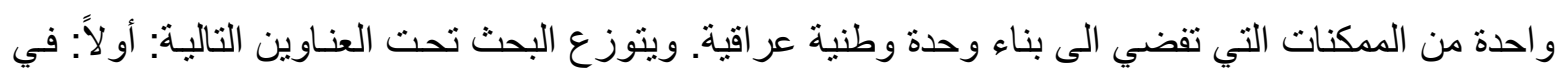

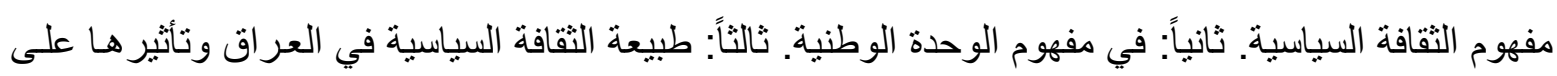
الوحدة الوطنية العر اقية. ر رابعاً: ممكنات بناء الوحدة الوطنية في العراق. خامساً: دور الثقافة السياسية في بناء الوحدة الوطنية العر اقية.

\section{أولاً: في مفهوم الثقافة السياسية:}

ترتبط الثقافة بشكل عام بالبيئة، فالبيئة واحدة من المتغيرات التي تشكل ثقافة الفرد، لأن الثقافة لا

تتتقل بالور اثثة، بل عن طريق الاكتساب و التحصل و الجهد النظري و الفكري من خلال قنوات أهمها: التربية و التعليم و التلقين والمعايشة والتنشئة الاجتماعية والسياسية('). ومن ثم فأن الثقافة تر اكم إبداعي عبر مسيرة

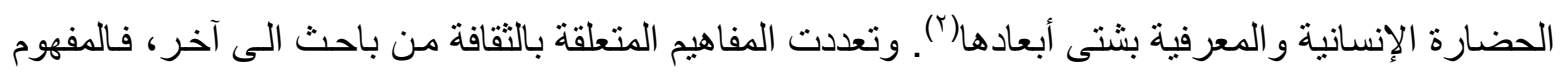
العام للثقافة اصبح يُغطي نو احي الحياة المختلفة من سياسية واجتماعية وثقافية و اقتصـادية("). ومن المفاهيم

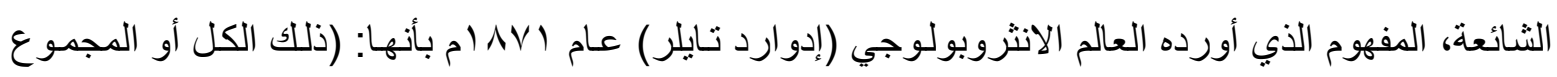


المعقد الذي يشمل المعارف و العقائد والفن والحقوق و الأخلاق والعادات والقانون ، وكل مهارة او عادة أخرى

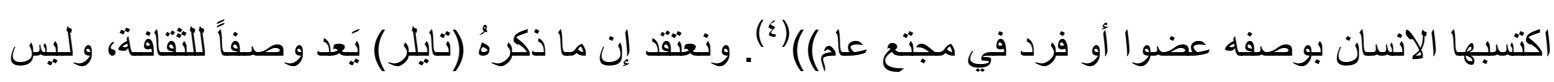
مفهوماً بمعنى آخر هو تعريف للتقافة، فمفهوم الثقافة هي عمليـة نقد مستمر للظو اهر والأشياء بمـا يمتلكهُ المثقف من الأفكار و التصور ات و انساق التفكير (ْ). و على وفق تعبير (تايلور) فأ، الثقافة تتصل بالنشـاط الإنساني كله، وبمـا إن السياسـة علم من العلوم

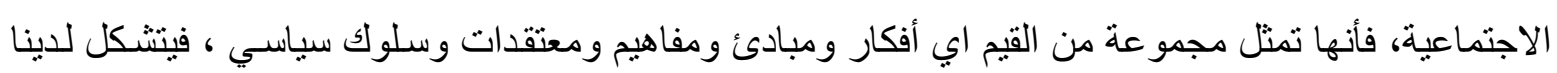

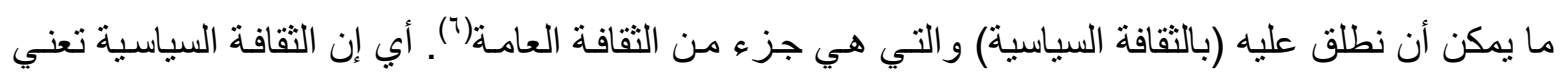
طر ائق التفكير والثعور و السلوك السياسي، هذه العلاقة بين الثقافة السياسية والثقافة العامـة تتماثـى مـع علم

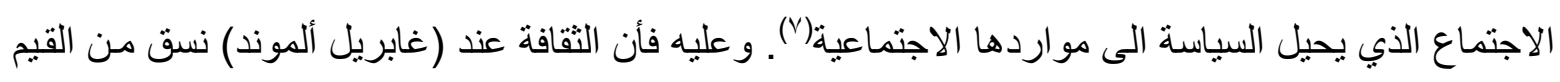

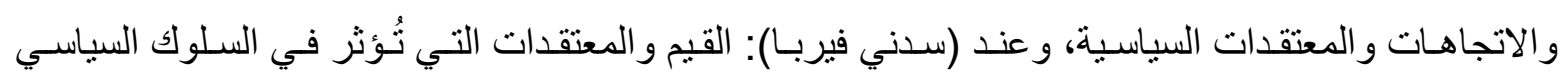
لأعضاء المجتمع سواء أكانوا حكاماً أم محكومين، أما (لوسيان باي) فهي عنده: مجموعة من القيم و المعتقدات

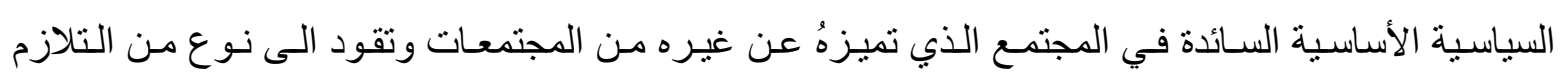

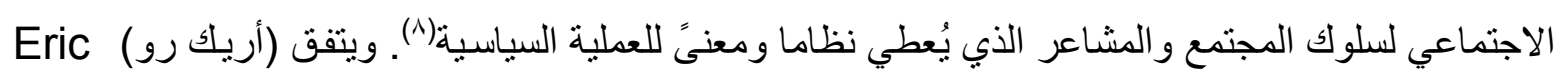

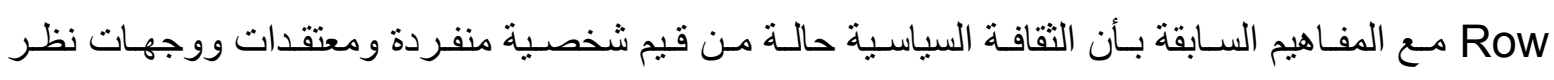
وتوجهات عاطفية(9). إلاّ إن أهم مقاربة علمية للتقافة السياسية هي تلك التي قام بها كل من (غابريل الموند

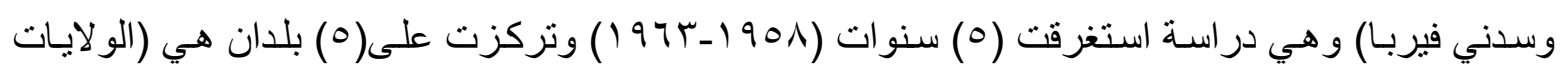
المتحدة ، المملكة المتحدة ، المانيا ، ايطاليا ، المكسيك) فأنطلقا أولا من إن الثقافة السياسية تحتوبي على ثلاثة

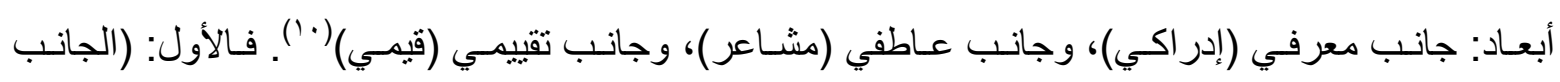

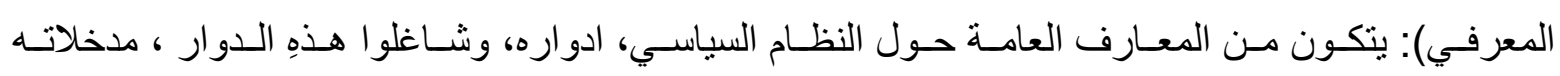
ومخرجاته، اي كل مـا يعرفهُ الفرد ويعتقد إنـهُ يعرف عبر المؤسسـات والأحزاب السياسية ورجـال السياسـة. و الثاني: (الجانب العاطفي) الذي يتعلق بـالو لاء الثخصـي للزعماء و المؤسسـات السياسية، اي المشـاعر اتجـاه

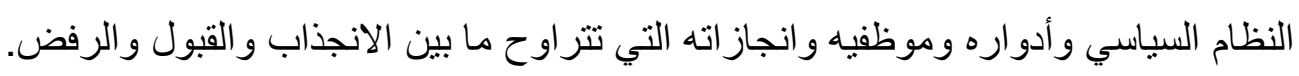
و الثالث: (التقييمي) أو (القيمي) : الذي يتضمن الأحكام القيمية حول الثأن السياسي من قيم ومعتقدات ومبادئ ومُتُل عليا والأيديولوجيا التي تؤثر في السلوك السياسي('). وبشكل عام، فإن الثقافة السياسية هي مجمو عة من الإدر اكات و المشاعر و القيم التي يختزنها الفرد إزاء النظام السياسي.

\section{ثانيا: في هفهوم الوحدة الوطنية:}

تعد مسـألة الوحدة الوطنية من المسـائل الجو هريـة في حياة الدول و المجتمعات ، وتأتي أهميتها من كونها غاية ووسيلة في آن واحد، فهي غايـة تطمح اليها (المجتمعات) و الدول ، ووسيلة ترتكز اليها لتحقيق

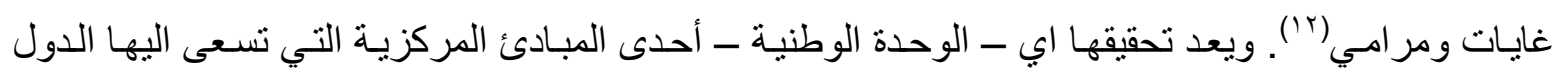

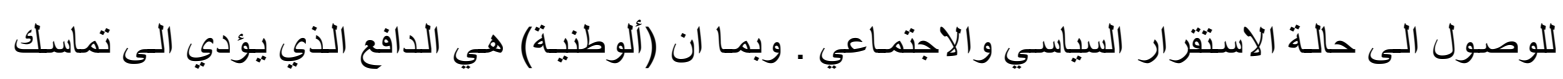
الأفر اد وتوحدهم و الى و لائهم للوطن وتقاليده والدفاع عنه "فالوحدة الوطنية إذن هي طبيعة العلاقات المتماسكة 
و الر ابطة بين الأفراد في مجتمع ما بحيث تجعله منضـامناً موحداً وقويـاً لتحقيق آمالـه وطموحاتهـ(r'). على إن

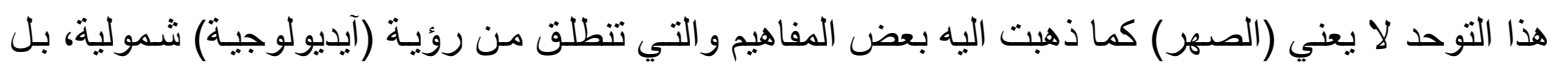

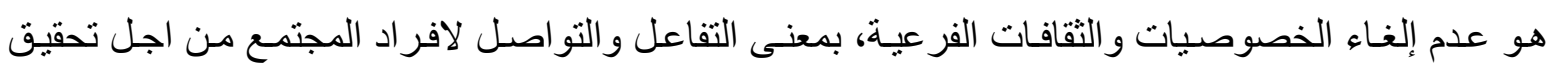
المصـالح و الأهداف المشتركة للجماعـات المختلفة ضـمن إطـار نظـام سياسـي بمـا في ذللك الثـعور بالاتنمـاء و الو لاء للوطن طوعاً وليس كُر هاً أو إجبـارًا، لأن الوسيلة الطوعية هي الأكثر ديمومسة واستقر اراً واستمر اراً

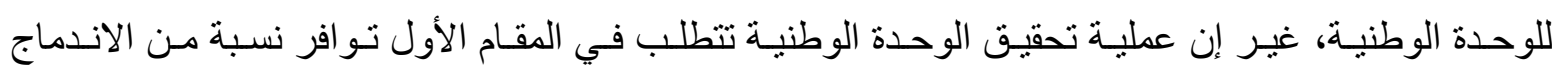
الاجتمـاعي الوطني* الذي يسبق عملية تحقيق أو بنـاء الوحدة الوطنية، فبحسب (ريساض عزيز هـادي) فأن الاندماج هي العملية التي تتمثل بادخـال كل من الأجزاء المختلفة داخل الكل ووضـع كل من هذه الأجزاء

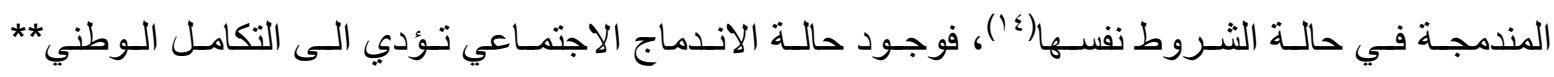
الاجتماعي ومن ثم الوحدة الوطنية.

إذن، فالوحدة الوطنية هي الأتفاق الطوعي و المشترك للتعددية الاجتماعية والسياسية على اسس العمل السياسي و الاجتماعي المشترك القائم على مبدأ المواطنة والمساواة والحرية و الحقوق والو اجبات كحد أدنى من الاتفاق و التي تخدم الخصوصيات الثقافية لكل جماعة اجتماعيـة وثقافية فرعية في إطـار المجتمع وفي إطسار الثقافة الوطنية العامة(10).

\section{ثالث): طبيعة الثقافة السياسة في العراق وتأثيرها على الوحدة الوطنية العراقية:}

لقد ورث العر اق (ومنذ تأسيسه كدولة في العصر الحديث) حالة من التخلف في مختلف المجالات بما

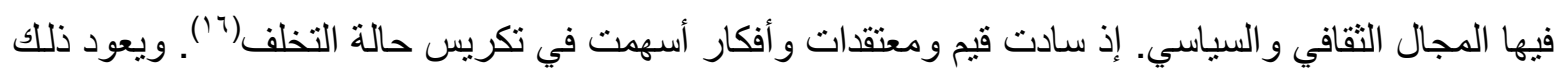

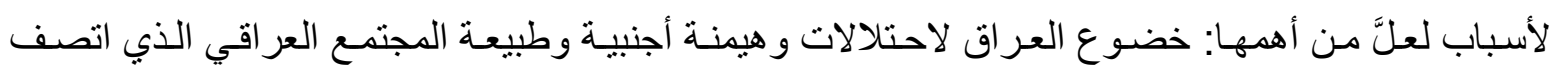

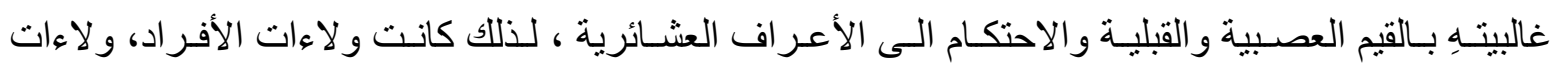

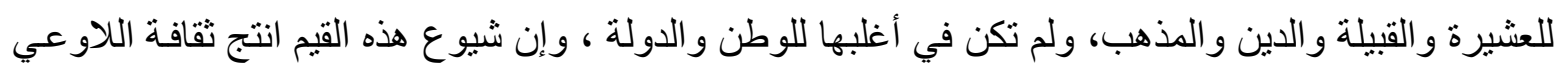

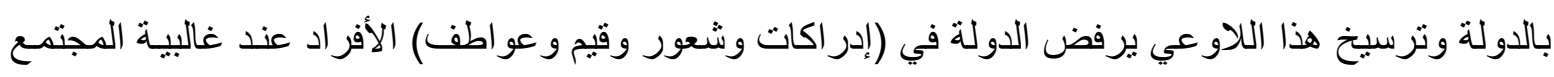
العر اقي، لطول عهد الاستبداد، واستمرت هذه الذهنية وآثار ها بقدر مـا الى الحاضر ، لذلك نجد وبشكل عامل إن الفرد العر اقي يعطي و لاءه و انتمائه للعشيرة(Y')، و القبيلة قبل - الوطن - ومثنل هذا تهديد خطير على قيم

الوحدة الوطنية العر اقية(1).

إن الوعي السياسي و الثقافي كان في جانب كبير منهُ يعكس الثقافة التقليديـة والخضوعية ، و التي هي

بالنتيجة ضد التجديد والحداثة، ولم تسعف هذه التقافات في إقامـة بنيـة سياسية / وطنيـة / عر اقيـة /مؤسسية/

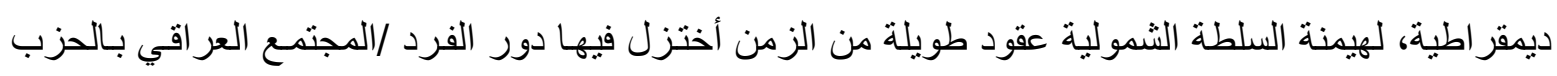

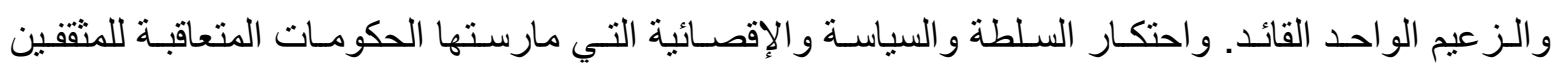
و الوطنيين، مما أدى بالبعض (وتحت ضغوطات السلطة ) إلى تغليب المصلحة الفئويـة والثخصية و المناطقيـة

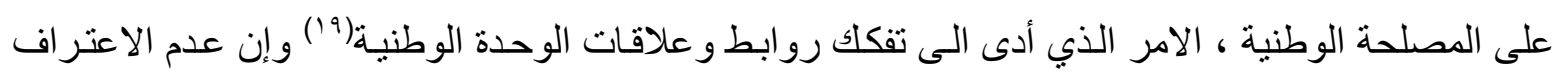

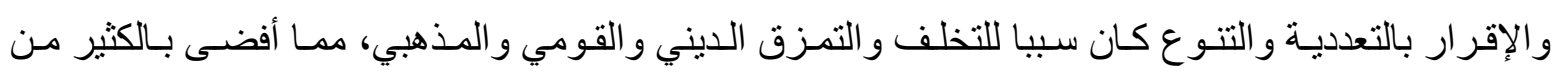


الأقليات الى الانعز ال و الانكفاء على نفسـها بمعزل عن محيطها العربي و الإسـلامي، وعدم اكتر اثها بشكل

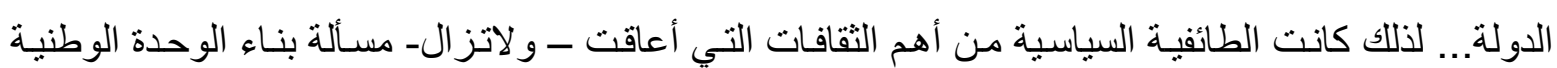

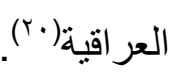

و عليـه، فأن الثقافة السياسية وفي ظل الحقبة السياسية الثمولية، ثقافة خضوع التي تنكر على العقل،

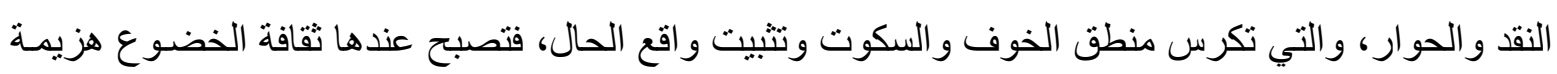
للانسان والفكر وقوى الثعب، و هذه الثقافة لا تلائم ولا تستو عب منطلبات بناء وحدة وطنية عر اقية.

لقد جُيرّت المؤسسـات الثقافيـة وأغلب المثقفين لتوجهات السلطة الثـمولية السـابقة ، و انصب اهتمسام

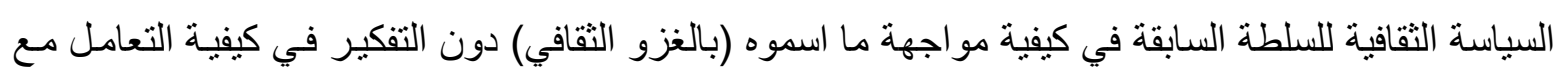
[الثقافة الو افدة و الاستفادة منها] (r). وسبب ذلك لأنهُ بـات يشكل خطر العلى قيم السلطة الثمولية ، لأن الفكر و الثقافة الو افدة كانت تتركز على قيم حقوق الانسان و الديموقر اطية و المجتمع المدني. أمسا المثقفون العراقيون وفي علاقـاتهم بالسـلطة فقد توز عت باتجاهـات مختلفة ، فـلأن المثقف الملتزم يعمل على نشـر ثقافة الجهـة

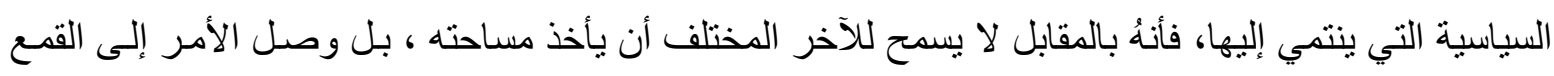
و الأرهاب بحق المختلف من لدن السلطة ، الأمر الذي أدى إلى انخر اط بعض المثقفين وعن طريق (الإغراء

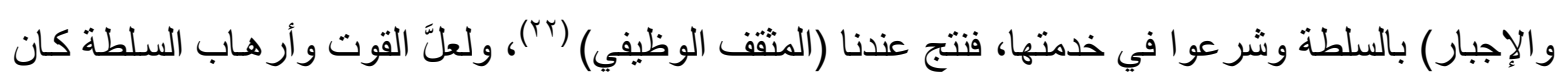
من أهم عاملين في سكوت المثقف ، فلجأ الى الكتابة غير المباشرة (السريالية) خوفاً من الرقابة. إن أحدى محن الثقافة العر اقية تتمثل في حالـة الخنق الدائم الذي لايُمكّن المثقف من التنفس بحريـة

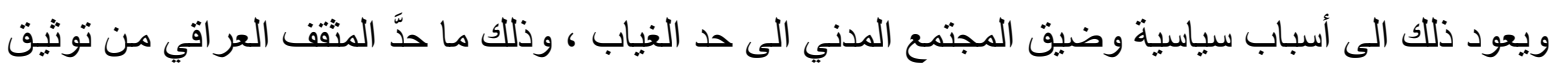

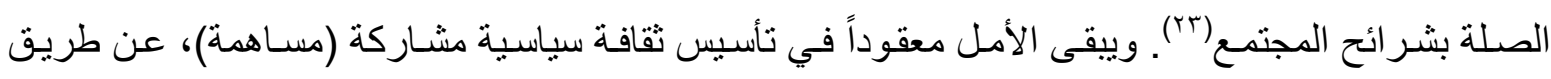
تحقيق كل من حقوق المواطنة والمشاركة في صنع القرار، أهم عاملين في خلق الثقافة السياسية المشـاركة، كتعبير عن مصـالح الإنسـان العر اقي والدفاع عن القيم الإنسـانية ، ور ايـة تبشـر بالعقلانيـة. كذللك تدافع عن الفن

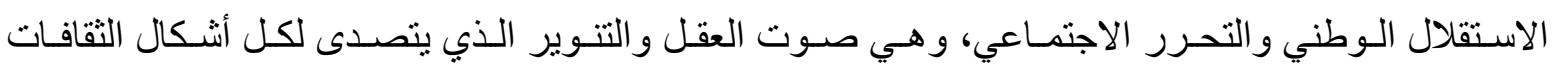

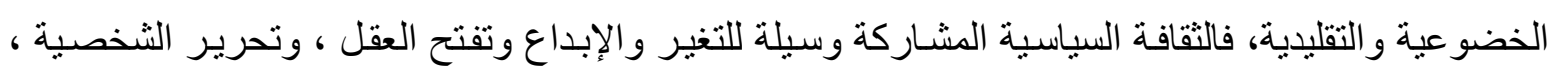

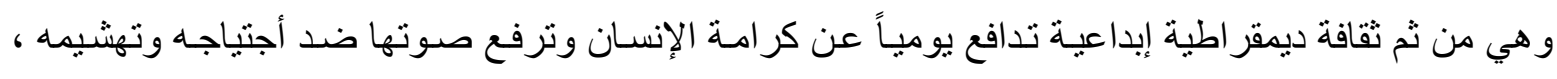
فهي مستلزم من المستلزمات السياسية لحل إثكالية الوحدة الوطنية في عر اق اليوم و الغد..!!

\section{رابه: ممكنات بناء الومدة الوطنية في العراق}

تعد مسألة الوحدة الوطنيـة العر اقيـة من أكثر المسائل أهميـة في مرحلة مابعد التغيير السياسي في

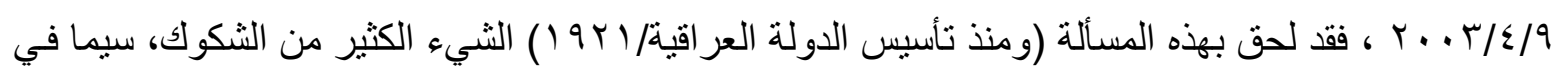

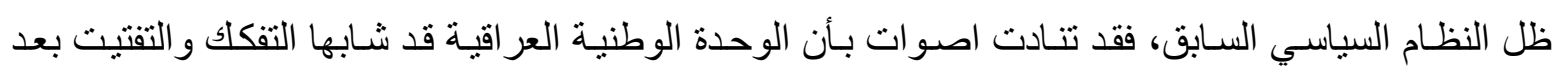
التغيير السياسي، وحجتها في ذلك بأن طيلة مدة النظام السياسي السابق كان العراق يتو افر على وحدة وطنيـة ،

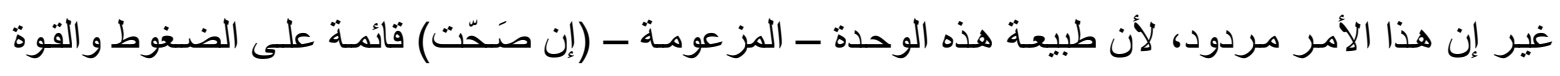
والصهر الفكري /الايديولوجي / والقومي الذي تبناه النظام ، واستخدم مختلف الأسـاليب و الوسـائل والآليات 
الثقافية/ السياسية التي من شأنها إخضاع كل الأفكار و الانتماءات الفرعيـة الى أفكار الحزب القائد ، وللدلالة على ذللك ما ظهر على السطح و اضحاً بعد التغيير وانهيار النظام السياسي السـابق، (عندما بدأ نشكيل صورة

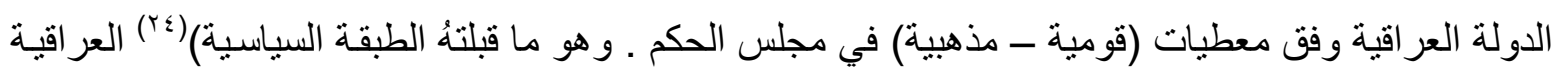
بعد ذلك ـ فلو كانت ثمـة وحدة وطنيـة عر اقيـة ماتلـة في الذهن و الثـعور والإدر الك لمـا قبلت الطبقة السياسية و الرموز الاجتماعية والثقافة العر اقية ذلك التوزيع القومي/ الطائفي في مجلس الحكم. وهذا يؤشر بشكل واضـح

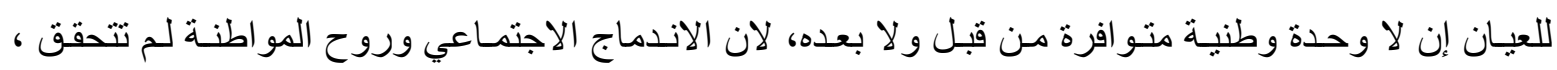
فكيف بالوحدة الوطنية؟؟.

إنَّ هذه الصـورة السلبية والقاتمـة هي الصـورة الواقعية في عراق الأمس و اليوم، فليس من التشــاؤم و السلب أن تقوم بإماطة اللثام عنها وتحليلها وبذلك نشخص المرض الاجتمـاعي الثقافي/ السياسي في العر اق،

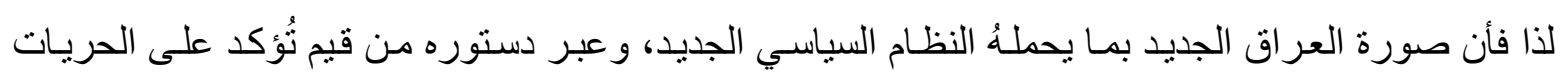

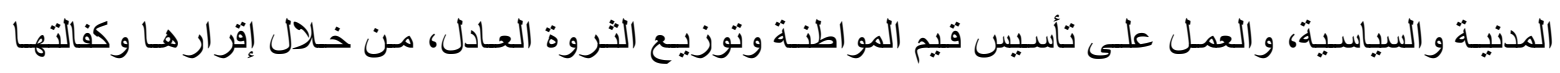

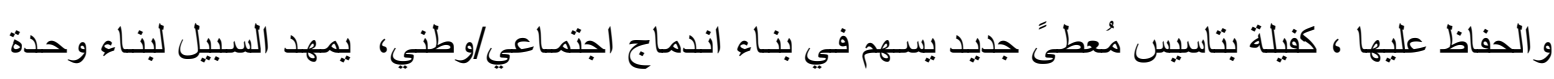
وطنية عراقية.

إن ثمة من الممكنات يمكن العمل بها لبناء وحدة وطنية عر اقية أهمها:

\section{ا - اـ على المستوى السياسي:}

ا ـ أن تو افر نظام سياسي ديمقر اطي برلماني تعددي، يوفر الضمانة الدستورية والقانونية لمشـاركة الثـعب في صنع القرار السياسي، كفيل بوضع أساس متين لبناء وحدة وطنية عر اقية(ro). r- بناء جّدي وموضوعي لمؤسسات سياسية وطنية تعبر عن وظيفة ومهمة تتجسد في خدمة المو اطن العراقي بغض النظر عن الانتماءات. r- تجاوز حالة - التوافقبة السياسية أو (المحاصصة الطائفية) التي عبّرت عن حالة من الثلك وعدم الثقة بين

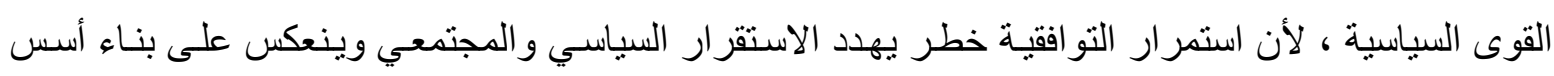
الوحدة الوطنية العر اقية، ومن ثم خطر يهدد التحول الديمقر اطي. عـ تطوير قدرة النظام السياسي على ممارسة سلطته السيادية على كافة أرجاء البلاد قانونيا ودستورياً بشكل فعلي ، لأن اي انحسـار في قدرة النظـام على فقدان زمـام السيطرة سيعرض البلاد الى التهديد بالانفصـال أو التمزيق.

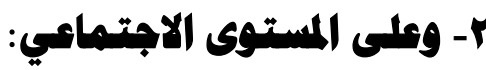

ا ـ تتمية الرو ابط بين الجماعات العر اقية كافة، بما يؤدي الى تلاحمهم و اندماجهم في كيان (سياسي/ اجتماعي) و احد، بمعنى الو لاء للوطن أولا بغض النظر عن الو لاءات الفرعية، عن طريق وسائل وأساليب عديدة أهمها :

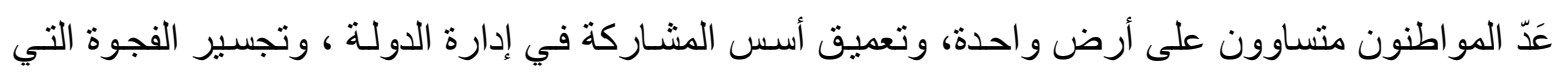


كانت قائمة ما بين المجتمع و الدولة، وهو ما بدأت ملامحه لتحقيقه في أن تكون السلطة وليداً شرعياً وطبيعياً

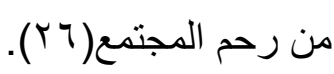
r- تفعيل أواصر العلاقات بين أعضـاء الجماعات الوطنية بهدف تحقيق مصلحة مشتركة للجميع، فالاهتمام بالمصلحة المشتركة تعد من الأسس المحفزة لبناء وحدة وطنية عر اقية. זـ العمل على تطوير وسائل الاتصال المتعددة بين المحافظات العر اقية ، لما للاتصال من وظيفة التقريب بين المواطنين في أرجاء العر اق كافة.

\section{r-وملى المستوى الاقتصادي:}

فمن المهمات الأساسية والجوهرية التي تقع على السلطة السياسية تحسين ظروف الحياة الاقتصـادية للمو اطنين كافة، من خلال القضاء على البطالة وتوزيع الثروة بعدالة، والاهتمام بدعم القطاع الخاص، و العمل على رفع وتائر العمل الانتاجي في المحافظـات كافة لجعل المواطن العر اقي بشـعر بقيمته وانتمـاءه وتمسكه بالوطن العر اقي.

\section{ع- وعلى المستوى الثقاني:}

ا ـ الاهتمـام بوسـائل وأسـاليب التتشئة السياسية/ الاجتماعية التي تعزز مـن قيم المواطنـة والارتبـاط بـالوطن و المو اطنة و الاندماج الوطني الاجتماعي بين أبناء المجتمع العر اقي من جهة وبين النظام السياسي من جهة أخرى.

ז- إن عمليـة بنـاء الوحدة الوطنيـة لا تتم بمعزل عن دور المجتمع، اي لا يقتصر على دور النظـام السياسـي

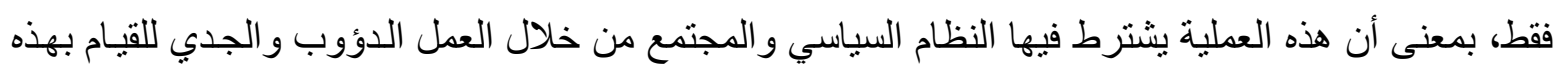
المهمة الجو هرية.

بـ إثـاعة وتشجيع روح المشاركة الجماعية ، لأن المشـاركة الجماعية تخلق روح المواطنة بين أبناء الوطن كافة ، وتجاوز حالة الو لاءات المحلية نحو الوطنية.

عـ تطوير وتفعيل دور منظمات المجتمع المدني في العراق كونها متغير ثقافي وسياسي واجنماعي تتجمع فيها وتتبلور مطالب المجتمع كافة دون تفريق بين مواطن و آخر.

\section{خامسك: دور الثقافة السياسية في بناء الوحدة الوطنية العراقية:}

تعد الثقافة إنتاج و إبداع بشري لايخضع للور اثثة. بل من خلال الاكتسـاب ، و لأن الثقافة السياسية هي

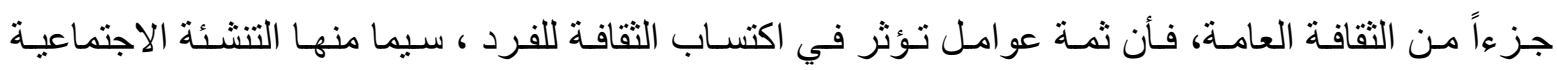
و السياسية والتي تعمل على رفع الوعي السياسي وجعلةُ مُؤثراً في قرار ات النظام السياسي (مخرجات) و التي تتجسد في مشاركته في العملية السياسية من جهة ، وأن يكون أكثر و عياً بتأثير السياسـات الحكوميـة عليه من جهة أخرى. وأن تكون لايه معارف سياسية ، أو يكون أكثر ميلاً للمناقثـة والحوار مـع الآخرين ، وأن يكون

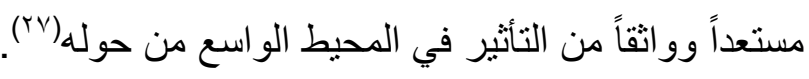


و لأجل أن تكون الثقافة السياسية في العراق مؤهلة الى رفع مستو اها الى حدث التأثنير في عمليـة بنـاء

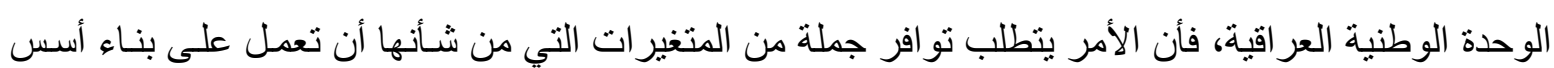
الوحدة الوطنية العر اقية.

اـ الاهتمام الجدي والفعلي في مسألة التنشئة الاجتماعية والسياسية في العراق بدءاً من دور الاسرة و المدرسـة

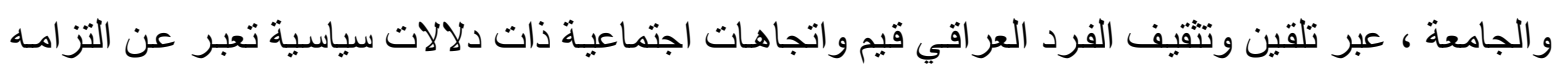
و اعتزازه بقيم الوطن و المو اطن و الوطنية والتمسكُ بها، ومن ثم الدفاع عنها ضد كل محاو لات الثقافة المضـادة

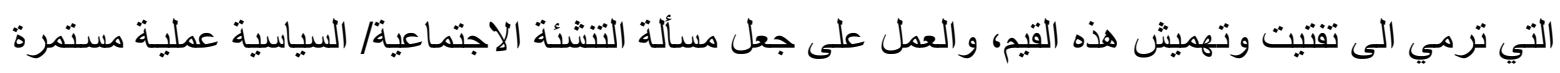
بدون انقطاع مهما تغيرّت الحكومات، فضلا عن انها هي العملية التي يتعرف بها الفرد على النظام السياسي و التي تقرر مدركاته السياسية، وهي تنطوي على دراسة الوسط الاجتماعي والاقتصـادي و الثقافي في المجتمع وتأثير ذلك على الفرد في مو اقفه وقيمه الأساسية(r^).

r- توسيع المشـاركة السياسية عبر انفتاح الأفق السياسي، وتجسيد ذلك بتوفير الحريـات المدنيـة والسياسية

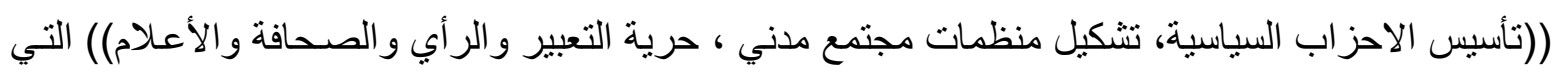

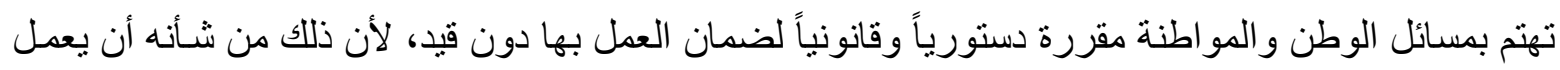
على تعميق روح الإقدام و المبادرة بالعمل الجماعي/الوطني، ومن ثم إثر اكهم في عملية صنع القرار السياسي من خلال المؤسسات السياسية.

rـ تتمية الاحساس بالهوية الوطنية العر اقية وتعزيز ها لدى جميع أفر اد الثعب العر اقي ، وهذا الأمر لايتم إلاّ بالتعاون بين النظام السياسي و المجتمع، من خلال زرع الثُعور بعامل الو لاء من جانب الأفراد للنظام السياسي الديمقر اطي ، عندما يستو عب هذا النظام مطالب الأفراد ويحولها الى قرار ات سياسية (مخرجات) تهنم بالثـأن

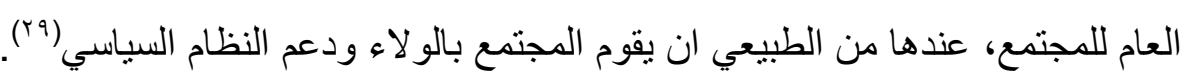
عـ تجاوز أو عبور حالة الثقافة السياسية التقليدية والخضوعية الى حالة الثقافة السياسية المشـاركة ــ المسـاهمة ـ للمجتمع العر اقي ، والتي من شأنها أن ترتفع بالمستوى السياسي العر اقي الذي يُؤهل افر اده الى تبني مو اقف

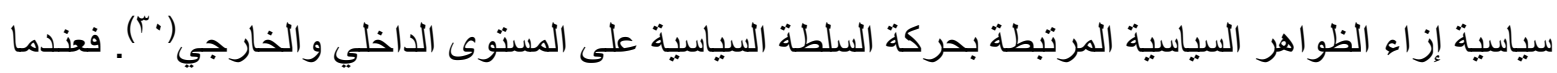
تسود المجتمع ثقافة سياسية مشاركة فأنها تعزز قيم سياسية تضغط باتجاه الامتثال لقرار ات السلطة السياسية التي يجب أن تمثل مصلحة المجتمع العر اقي عامة من جهة، و انفتاح السلطة السياسية على المجتمع العر اقي من جهة اخرى. وهو ما يجعل العلاقة بين المجتمع والسلطة أكثر عمقاً ونضجاً وتفاعلاً وتعاوناً. هـ إن شـرعية النظام السياسي من المرتكزات الأساسية في شـعور الفرد العر اقي بالرضـا والقبول الطوعي و الاختياري لهذا النظام ، بمعنى اختيار الثعب للنظام السياسي وقبوله. ان تقديم النظام السياسي خدماته للشعب يجسد المحتوى الوطني لهذا النظام ـ ومن ثم بناء أسس متينة للوحدة الوطنية العر اقية بحيث بثـعر الجميع بـأن النظام السياسي يعمل على خدمة المجتمع ويستو عب مطالبه، ومن هنـا ، فأن شر عية النظام لا تتجسد بـالفوز في الانتخابات فحسب، بل بما يقدمه النظام من انجاز ات حكومية تسهم وتستهدف الصالح العام. 
7- إن ارتفاع مستوى الوعي السياسي للأفر اد يجعل من عملية التفكير بوظيفة ومهام السلطة السياسية من شؤون الفرد السياسية، فامتلاك الفرد الثفافة السياسية التي تجعلـهُ في موقف الناقد أو الداعم للسلطة السياسية باتجاه جمعي / وطني، كفيل ببناء أسس الوحدة الوطنية العر اقية.

V- بناء الثقة بين النظام السياسي والمجتمع و التي من شأنها الإسهام بيناء الوحدة الوطنية العر اقية، وهذا الأمر

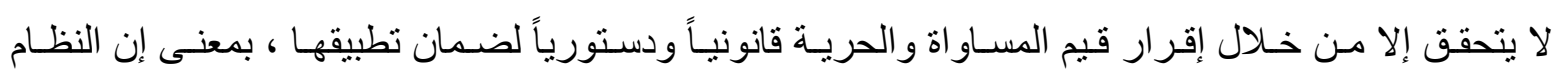

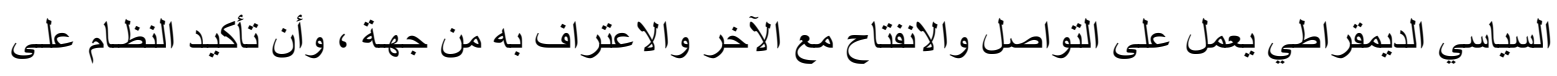
أهمية الحرية كقيمة سيسهم في بناء ثقافة سياسية مشاركة (ديمقر اطية) من جهة أخرى، ومن ثم تستطيع هذه

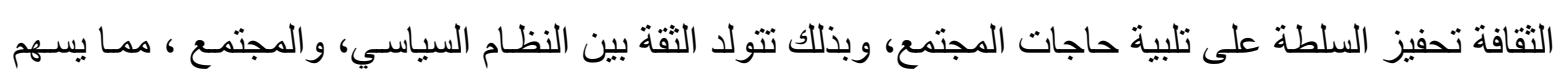
في بناء وحدة وطنية عر اقية .

^- إن الاهتمـام بمسـألة (المواطنـة) مـن المسـائل الجوهريـة في بنـاء الوحدة الوطنية العر اقيـة ، فتو افر حقوق

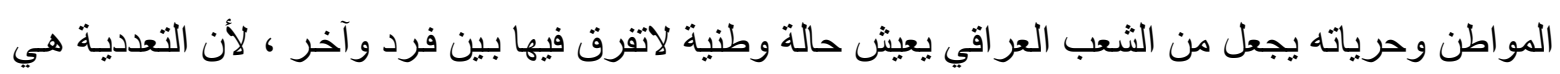
حالة طبيعية في المجتمعات ، ومبادئ الدستور و القوانين هي التي تكفل منح وتطبيق هذه القيم ، ومن ثم تحقيق

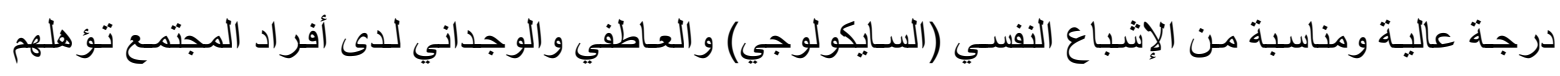

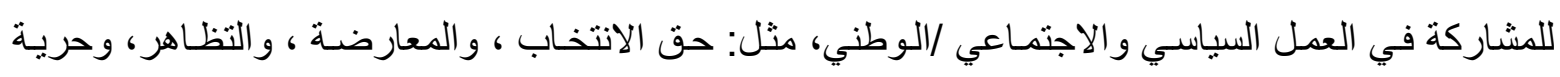
التعبير عن الر أي ، كل هذه من شأنها خلق قيم على طريق بناء الوحدة الوطنية العر اقية. 9- إن قيام النظام السياسـي بالثروع بتتميـة شـاملة تهنم بالإنسـان بوصفه عضواً في المجتمع، من شـأنها أن يسهم بشكل جاد في بناء وحدة وطنية عر اقية.

الغـاتمبة

من الظوا اهر الملفتة للنظر في عالمنـا المعاصـر، سـي الثقافـات لأن ترتفع الى المستوى السياسي،

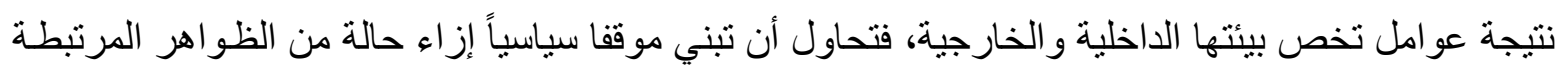
بالسلطة السياسية على المستويين الداخلي والخـارجي وهي بذللك تعبر عن أفكار وقيم ومبادئ وتوجهات

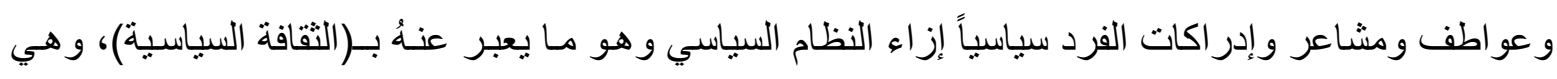

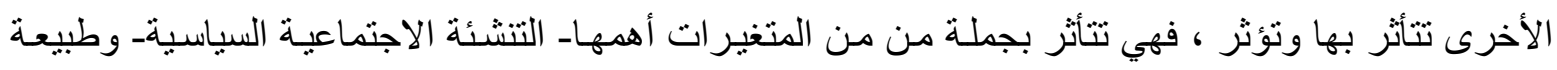

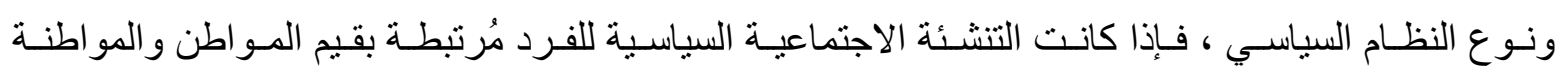
و الوطنية، وفسح المجال السياسي أمام المواطن قانونياً ودستورياً من قبل النظسام السياسي سيؤدي الى تهيئة المناخ الوطني لكي تعمل الجماعـات تحت خيمة الوطن الواحد على أسـاس المصـالح المشتركة، و هي تؤثر كذللك في محبط المجتمع كما في النظسام السياسي، فمخرجـات التنشئة الاجتماعيـة/ السياسية وطبيعـة النظسام السياسي الذي يُؤكد ويقر ويعترف ويكفل الحقوق المدنية والسياسية ستفضـي الى بنـاء أسس الوحدة الوطنية العر اقية. 
وفي حالـة العراق، فأن عمليـة عبور أو اجتياز حالـة الثقافـة التقليديـة والخضـوعية الى حالـة الثقافة السياسية المشـاركة ـ المسـاهمة ـ تتطلب تو افر مستلزمات ومتطلبات أهمها: مغادرة الفكر الثمولي ومنح الحريـات و الحقوق المدنيـة والسياسية، وزرع قيم المواطنـة في نفوس أفر اد الثـعب العر اقي على المستوى

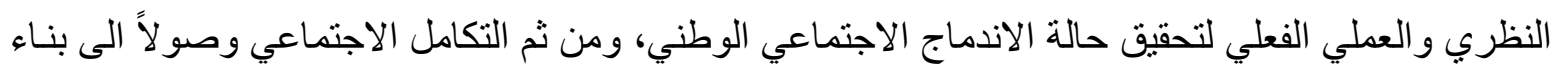
أسس الوحدة الوطنيـة العر اقيـة، فالتقافة السياسية المشـاركة واحدة من العو امل المهمهة و الجو هريـة في بنـاء الوحدة الوطنية العر اقية.

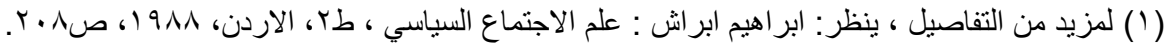

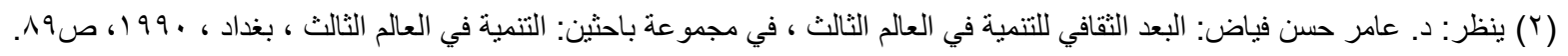

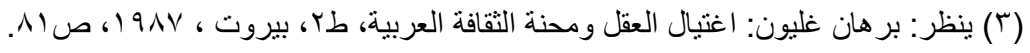

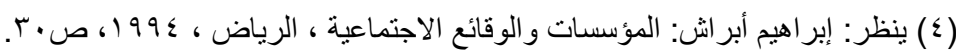

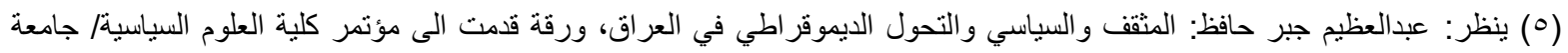

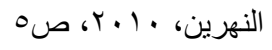
(ך) ينظر: عبدالعظيم جبر حافظ: التحول الديموقراطي في العراق ، (الو اقع و المستقبل) ، تقديم: د. فالح عبدالجبار ، مؤسسة مصر مرتضى

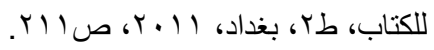

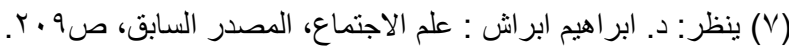
(^) ينظر: هشام حكت عبدالستار: الديمقراطية واشكالية الثقافة السياسية في الوطن العربي، اطروحة دكتوراه غير منشورة، كلية العلوم

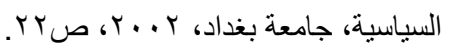
Eric Row: modern politics , An introduction behavior and institution, New York , humarities : (9) press, 1969, p. 12-13.

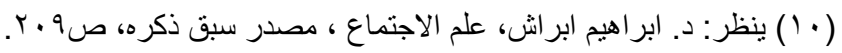

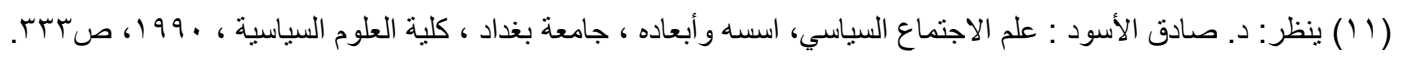

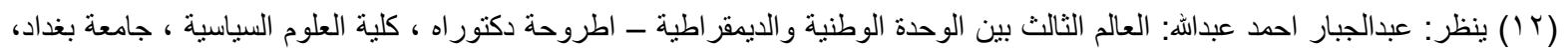
...

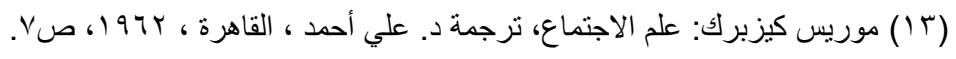

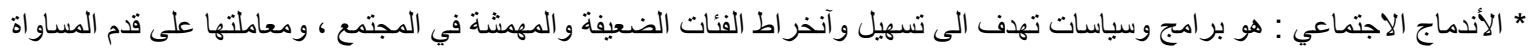
مع افر اده، وتنظيماته طبقاً لقو انينه.أي أنها سياسة إثر الك مجمو عات إثنية في حياة المجتمع الكلي ، وهي في في الممارسة الو اقعية مساواة

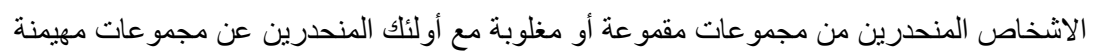

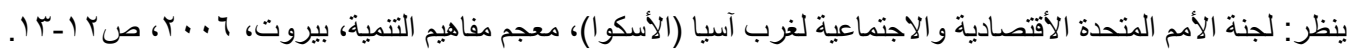

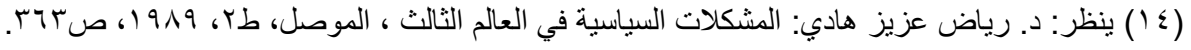

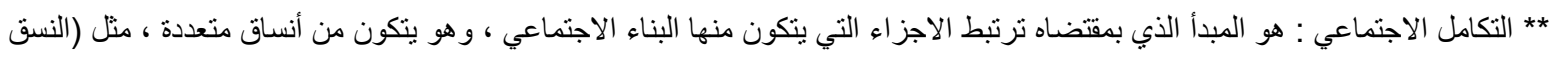

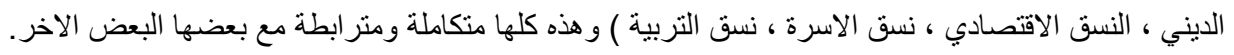

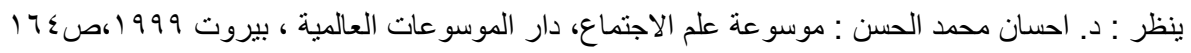
(0 1 ) ينظر: زيد عدنان محسن العكيلي : الثقافة السياسية والوحدة الوطنية في مصر و السودان، رسالة ماجستير ، كلية العلوم السياسية، جامعة

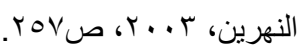

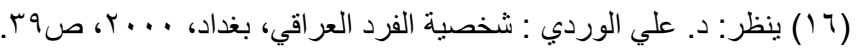

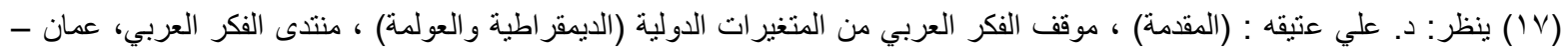

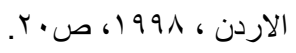




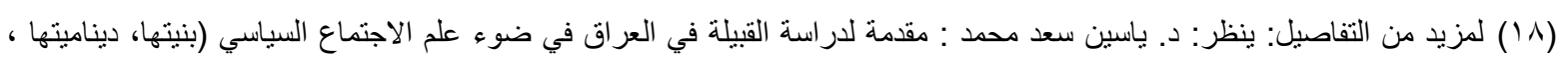

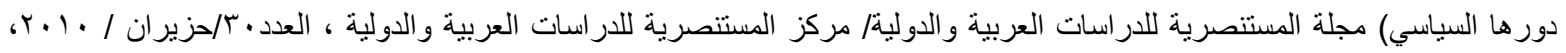
ص صـ-11) (9 1) لمزيد من التفاصيل حول هذا الموضوع ، ينظر: حنا بطاطو: العراق، الكتاب الأول ترجمة/ عفيف الرزاز، مؤسسة الأبحاث العربية،

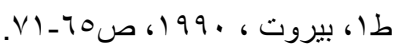
( • (Y) لمزيد من التفاصيل ، ينظر : د. حميد فاضل حسن ، الطائفية السياسية في العراق، مجلة العلوم السياسية ، كلية العلوم السياسية، جامعة

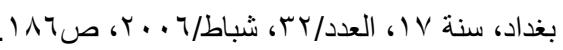

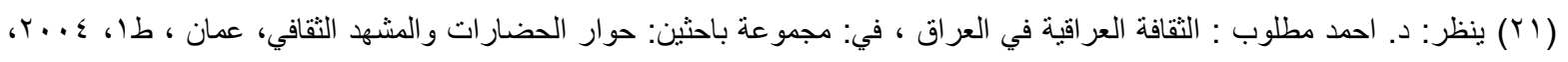

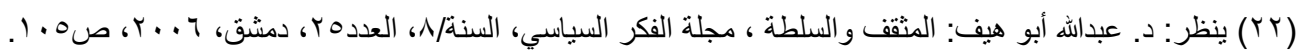

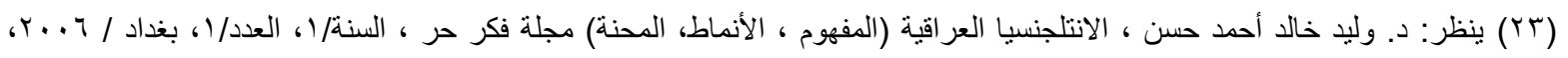
(ع (Y) ينظر: مجموعة باحثين : المواطنة والهوية العر اقية (عصف احتلال ومسارات الحكم): (من المقدمة) : اعمال المؤتمر الثالث لمركز

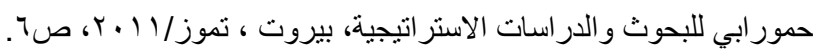

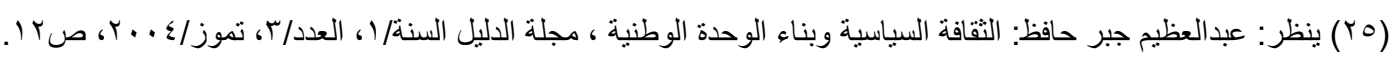

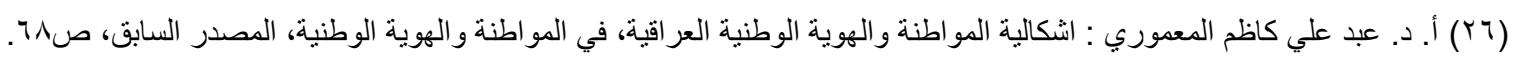

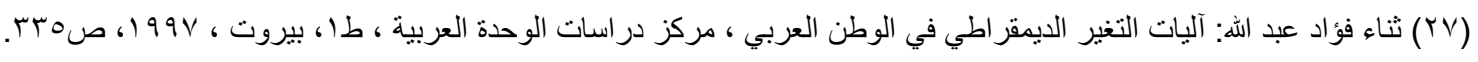
(Y^)

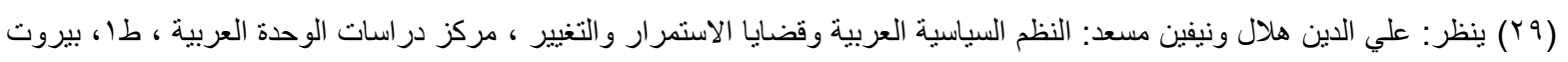
. $1 \varepsilon$ ص.... ، ( • (r) ينظر: عبدالعظيم جبر حافظ : الثقافة السياسية ، المصدر السابق، ص^.

\section{:}

I- ابر اهيم ابر اش: علم الاجتماع السياسي ، طY، عمان - الأردن ، I9AV.

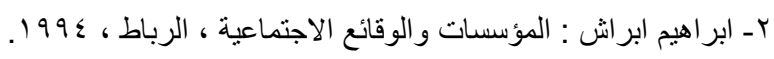

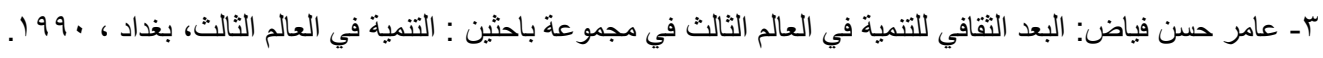

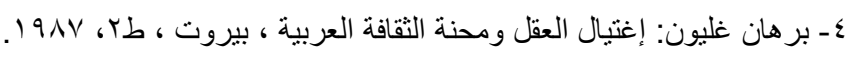

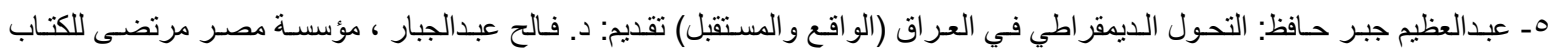

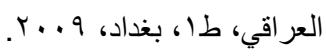

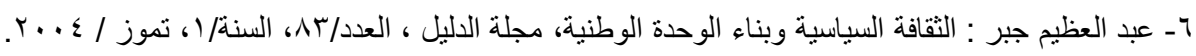
V- عبد العظيم جبر حافظ : المثقف و السياسي و التحول الديمقراطي في العر اق ، ورقة قدمت إلى مؤتمر كلية العلوم السياسية ، جامعة النهرين $r \cdot 1 \cdot 6$ ^- هشام حكت عبدالستار : الديمقر اطية و اشكالية الثقافة السياسية في الوطن العربي- اطروحة دكتور اه ، كلية العلوم السياسية ، جامعة بغداد، r...T

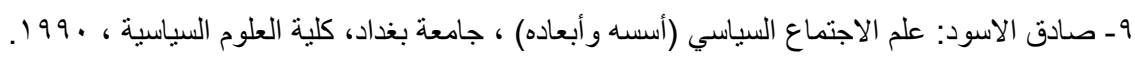

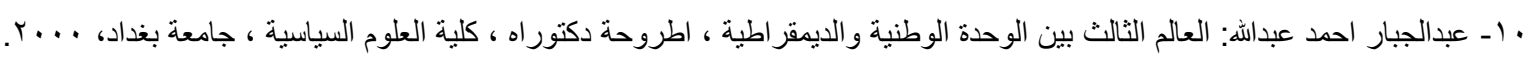

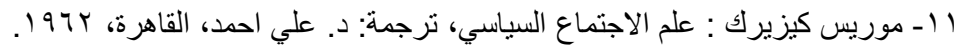

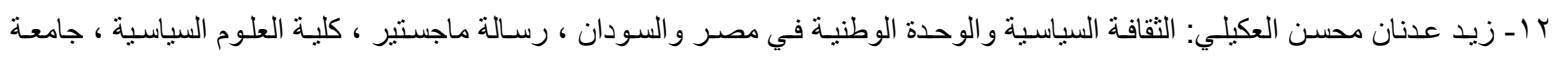

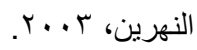

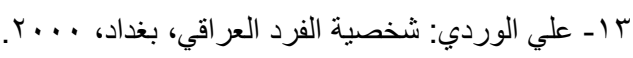

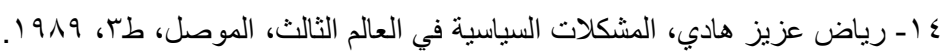




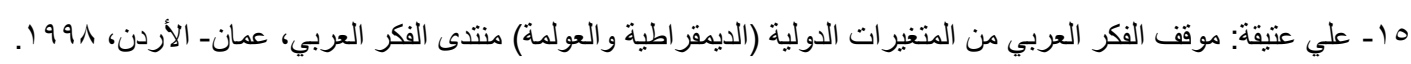

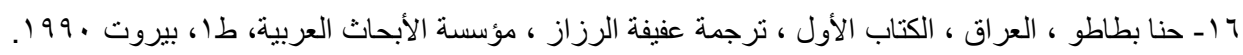

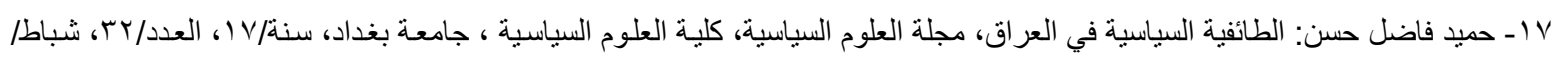
. . . T

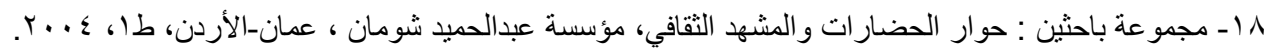

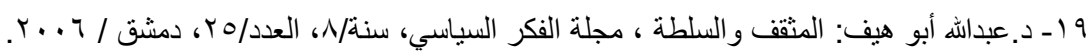

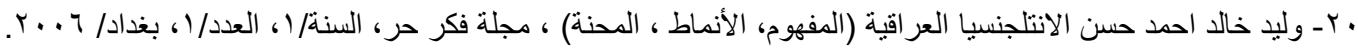

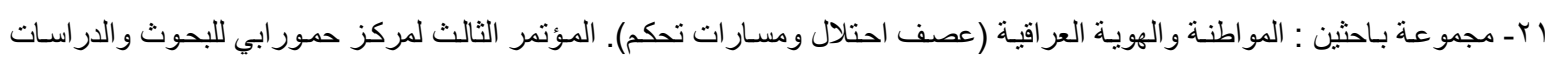

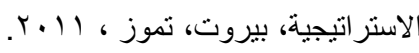

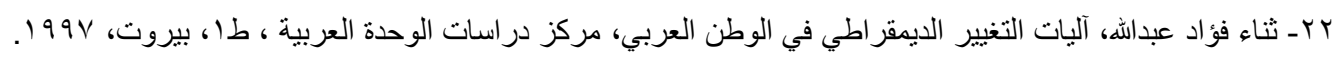

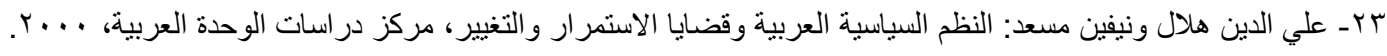

24- Eric Row: Modern politics, an introduction behavior and institution, New York, humarities , press 1969. 